\title{
A!
}

This is an electronic reprint of the original article.

This reprint may differ from the original in pagination and typographic detail.

Veske, Paula; Ilen, Elina

\section{Review of the end-of-life solutions in electronics-based smart textiles}

Published in:

Journal of the Textile Institute

Published: 26/09/2020

Document Version

Peer reviewed version

Please cite the original version:

Veske, P., \& llen, E. (2020). Review of the end-of-life solutions in electronics-based smart textiles. Journal of the Textile Institute.

This material is protected by copyright and other intellectual property rights, and duplication or sale of all or part of any of the repository collections is not permitted, except that material may be duplicated by you for your research use or educational purposes in electronic or print form. You must obtain permission for any other use. Electronic or print copies may not be offered, whether for sale or otherwise to anyone who is not an authorised user. 


\title{
Review of the End-of-Life Solutions in Electronics-based Smart Textiles
}

\author{
Paula Veske ${ }^{1}$, Elina llen² \\ ${ }^{1}$ Department of Electronics and Information Systems, Ghent University, Ghent, Belgium \\ ${ }^{2}$ Department of Design, Aalto University, Espoo, Finland \\ Corresponding Author: Paula Veske, Ghent University, Technologiepark 126, 9052 Gent-Zwijnaarde, \\ Belgium.

\section{E-mail: paula.veske@ugent.be} \\ Conflict of Interest Statement: The authors declare no conflict of interest.
}

Keywords: e-textiles, environmental sustainability, recycling, circular economy, waste management

\begin{abstract}
Research and development of new products in the smart textile field is growing rapidly because of versatile application areas. There is an extensive focus on the integration of electronics into textiles. However, if different fields are merged, as here, the sustainability and recycling issues might descend into even more complex systems. The paper reviews current research and development conducted on the end-of-life solutions for electronic textiles (e-textiles). Chosen papers had to be peer-reviewed, written in English, and address the end-of-life issue for electronic-based smart textiles. The search resulted in 18 publications, which indicates a low amount of research but also the serious lack of legislation and actual solutions emerged in this multidisciplinary field. Three main themes were found: smart textile services, eco-design strategy and educating guidelines. Authors suggest taking urgent actions by preventive steps in combining current electronics and textile waste management systems into one standard for e-textiles.
\end{abstract}

\section{TEXTILE INTEGRATED ELECTRONICS IN ECO-DESIGN CONTEXT}

Van Langenhove and Hertleer (2004) state "smart textiles are fabrics or apparel products that contain technologies, which sense and react to the conditions of the environment they are exposed to, thus allowing the wearer to experience increased functionality". The conditions or stimuli can be electrical, mechanical, thermal, chemical, or a combination of these. The main research in the smart textile field is indefinitely focused on improving the integration level, from moving from garment level to fibre level (Schneegass \& Amft, 2017). For example, Katashev et al. (2019) replaced conventional EIT (electrical impedance tomography) electrodes with knitted textiles electrodes where conductive parts are on fibre level. Electronic textiles (e-textiles) are a subcategory of smart textiles that are based on electronics and conductive textiles, e.g. silver-coated fabrics or yarns, conductive inks and/or conductive polymers (Stoppa \& Chiolerio, 2014). The E-textiles system includes the traditional electronic components, for example, printed circuit boards (PCB) and non-textile sensors that include ceramics in addition to metals and plastics.

In e-textile products, the level of integration has a remarkable influence on the materials' recyclability and the end-of-life solutions of the product. As a result, e-textiles require specified end-of-life treatment methods and standardized waste processing. It is vital to tackle the topic early to avoid mistakes made in textile waste management. End of product lifetime or EOL (End-of-Life) of the product is the point when it is not usable anymore or just not needed by the user anymore. Thus, it should be reused, recycled, remanufactured or 
disposed of (landfill or incineration). Duque Ciceri et al. (2010) proposed a tool and an overall outlook of EOL to give perspective to the environmental impact of any product. It is essential to define the product's EOL plan in the early stage before the manufacturing and commercialisation phases. Especially when the several industry fields are combined, e.g. in the case of e-textiles - textiles and electronics.

In the traditional linear lifetime economy, "from cradle to grave" based system does not consider the reuse of product or materials. However, the circular economy system for textiles and fashion items has been popularized since the early 2000s. Ellen MacArthur Foundation (2017) describes the circular economy (Figure 1) with three principles:

1) design out the waste and negative economic impacts;

2) designing for durability, reuse, remanufacturing and recycling to keep products in use;

3) using renewable resources and regenerate natural systems.

The system supports the sustainability of the fashion and textiles field with three key actions: scaling up shortterm clothing rental; making durability more attractive, and increasing clothing utilisation further through brand commitments and policy.

Eco-design concept follows the principles of the circular economy. The circular economy emphasizes the responsibility of each operator in the product value chain. The product eco-design considers the same issues, the sustainable impacts of materials, the longevity in the use phase, repairing or reusing when worn out or broken, but also the recyclability after the use; how the waste materials could be utilised as a source for the next cycle. Eco-design concept has contributed tremendously during the last decade into improving textiles environmental sustainability. Eco-design can be applied in different aspects and forms, e.g. design for disassembly, design for reuse or also design for recycling (Sanyé-Mengual et al., 2014). The EU directive 2009/125/EC - establishing a framework for the setting of ecodesign requirements for energy-related products (e.g. e-textiles) - has defined 'energy-related product' as "any good that has an impact on energy consumption during use which is placed on the market and/or put into service" ("Directive 2009/125/EC," 2009). The directive's aim is to set eco-design requirements for 'energy-related products' to contribute to sustainable development by increasing energy efficiency. Internationally, eco-design has been presented in ISO 14006 standard ("EN ISO 14006," 2011). The guidelines address eco-design as "a systematic approach that considers environmental aspects in design and development with the aim to reduce adverse environmental impacts throughout the life cycle of a product". It is also brought out that similar terminology includes "environmentally conscious design (ECD)", "design for environment (DfE)", "green design" etc. DfE

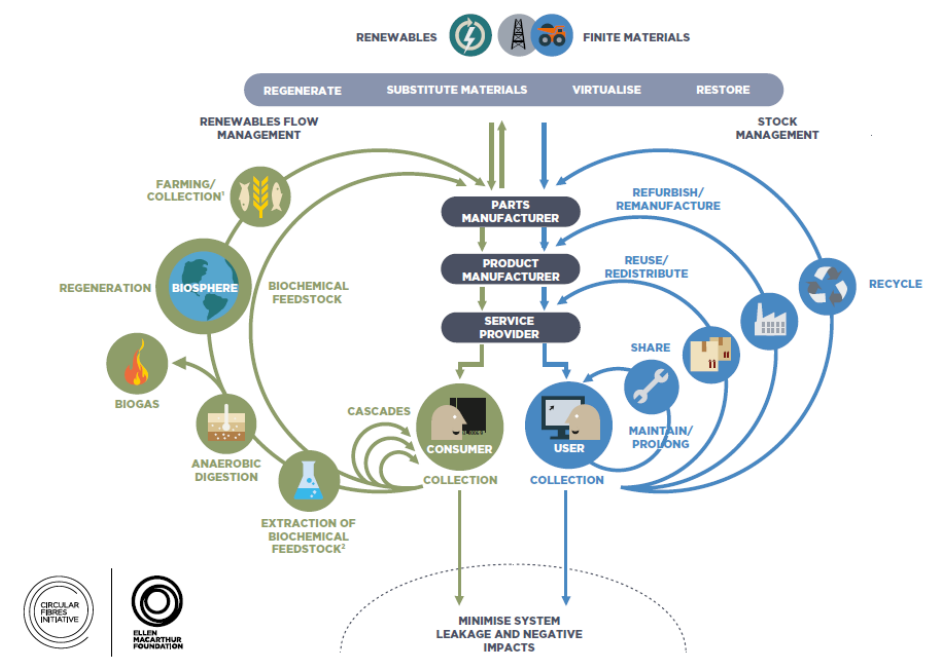

Figure 1. Circular economy system (Copyright @ Ellen MacArthur Foundation, 2017) 
It is important to focus on the early stage on the end-of-life issues since textile waste management is already an extensive issue. Even more so, the main part of e-textiles are textile materials - they are the carriers for electronics. Thus, the e-textile products are considered more as clothing pieces than purely electronic products.

In general, the consumption of textiles has been rising, mainly because increased prosperity has also in countries such as China that are beginning to approach European and American levels (Beton et al., 2014). In Denmark and Sweden, the consumption of clothing and household textiles has increased, respectively, by 62\% (2003-2008) and 40\% (the period 2004-2014) (Nørup et al., 2018). European Environmental Agency stated in a 2019 report that the EU (European Union) policies oblige the Member States to collect textiles separately and ensure that the waste collected is not incinerated or landfilled by 2025 (European Environment Agency, 2019).

The market indicates a growing demand for loTs and flexible electronics. It was estimated that the global smart textile market size is to reach 5.55 billion US dollars by 2025 (Grand View Research, 2018). Wearables goods are forecasted to increase to 150 billion dollars by 2026 from the estimated level of 30 billion dollars in 2016 (European Commission, 2016).

A report in 2015 suggested smart textiles and wearable electronics have a big impact on a variety of application areas, e.g. medical and fitness, automotive and military sections (Ruck, 2015). Thus, over the last 15 years, the European Commission has provided research and development increased funding for projects, including smart textiles and other smart systems.

Supporting and increasing the smart textiles field in Europe, the EU has funded several smart textiles projects to improve manufacturing competitiveness in Europe and raise awareness of collaboration between different fields.

Horizon 2020 was the most significant EU Research and Innovation programme with funding of 79 billion euros from 2014 to 2020. It promoted innovation and competitiveness to strengthen investment in R\&D and innovation in Europe (Vercruysse, 2015). Several great smart textile related projects and accelerators were set up, for example, WEAR Sustain and SmartX (European Smart Textile Accelerator) (SmartX, 2019; WEAR Sustain, 2018).

Prior to Horizon 2020, ten projects including smart textiles, flexible and wearable electronics were funded under FP7, the Seventh Framework Programme for Research and Technological Development during 20072013 (DG CONNECT, 2017). The FP7 resulted in prototype demonstrators, 3 spin-offs, 24 patents and 48 journal peer-reviewed publications and advanced the smart textile market remarkably.

Moreover, even funding for developing training curriculums on smart textiles, wearables and digital manufacturing called Education4Fashiontech was set up (Larsson et al., 2018). One of the objectives within the project was to develop an innovative curriculum encompassing smart textiles, wearables and digital manufacturing.

The market growth forecast and EU funding encourage the manufacturing of e-textile products. However, the life-cycle of these products is still vague since it combines at least two different fields: electronics and textiles. Before the fast market growth of textile-based wearables, it is crucial to define life-cycle processes for etextile products to avoid textile and, more specifically, fast fashion's great lack of recycling procedures.

Köhler et al. (2011) propose that e-textiles offer radically new ways for human-technology interaction. The user is influenced to commit to more sustainable behaviour by taking extensive care since the electronics embedded in clothing now has more value. Hence, the added value of the garment could extend its lifetime. Several studies on smart textiles for health care sector have been published that increase the value of the apparel and possibly prevent different medical problems (Carvalho et al., 2014; Castrillón et al., 2018; 
Glazkova et al., 2020; Ilen, 2015; Paul et al., 2015; Zysset et al., 2010). Meanwhile, sports applications concentrate on monitoring physical activity rate or improving technique and performance through wearables (Ferraro, 2015; Zhou et al., 2016). The creation of an autonomous system by kinetic energy harvesting from a human body is being studied extensively (Hou et al., 2013; Hu \& Zheng, 2019).

There are several examples of different integration levels in research and on the market (Figure 2-Figure 5). Still, only a few of them have considered the waste management and end-of-life of the product (Figure 4Figure 5). Suunto Movesense is one example of a state-of-the-art option on the market. Suunto Movesense Sports Bra in Figure 2 has the textile integrated electrodes and a small Movesense sensor for heart rate monitoring. The bra conforms with CE (Conformité Européene or European Conformity), REACH (Registration, Evaluation, Authorisation and Restriction of Chemicals), RoHS and also complies with CE, with addition to several other standards. Though their products' design considers everything removable, these standards are mainly only for electronic parts or equipment which are mandatory for everybody.

In Commuter Jacket with Jacquard threads and the Jacquard platform supported by Google and Levi's, (Figure 3) the conductive yarns are integrated into the fabric in the weaving process (Levi's \& Google, 2017). The main weakness of the product is that it lasts only 10 washing cycles, and there are no collection points for defective products.

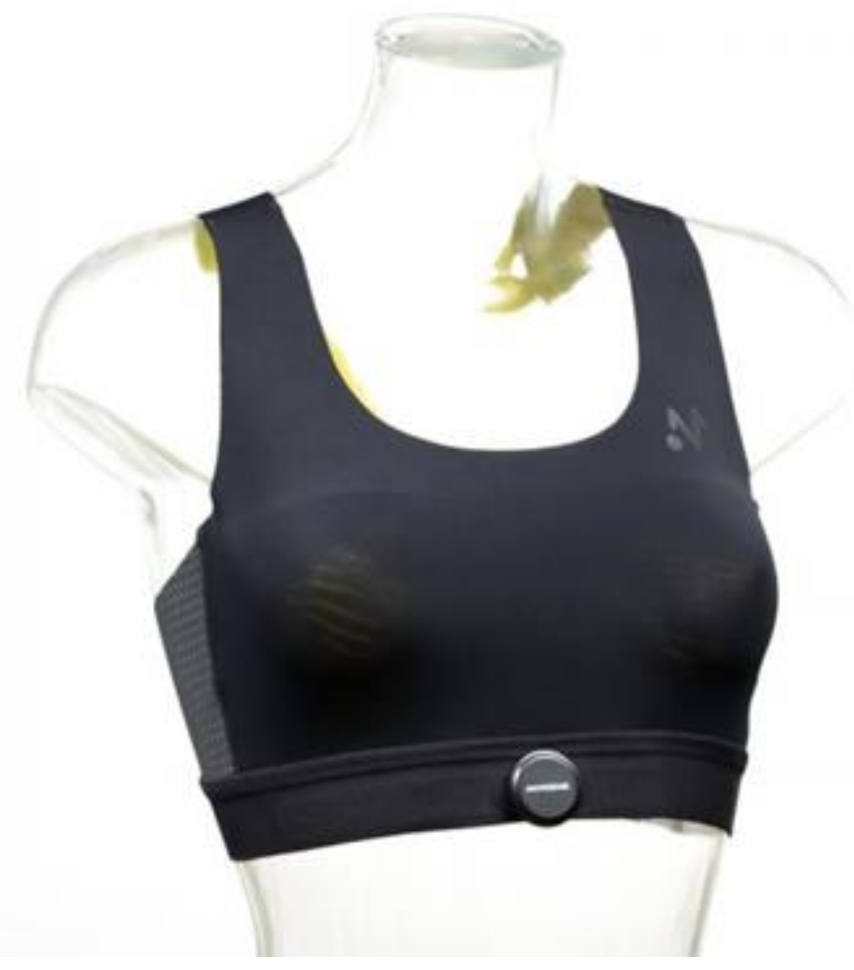

Figure 2. Suunto Movesense Sports Bra (Suunto, 2019) 


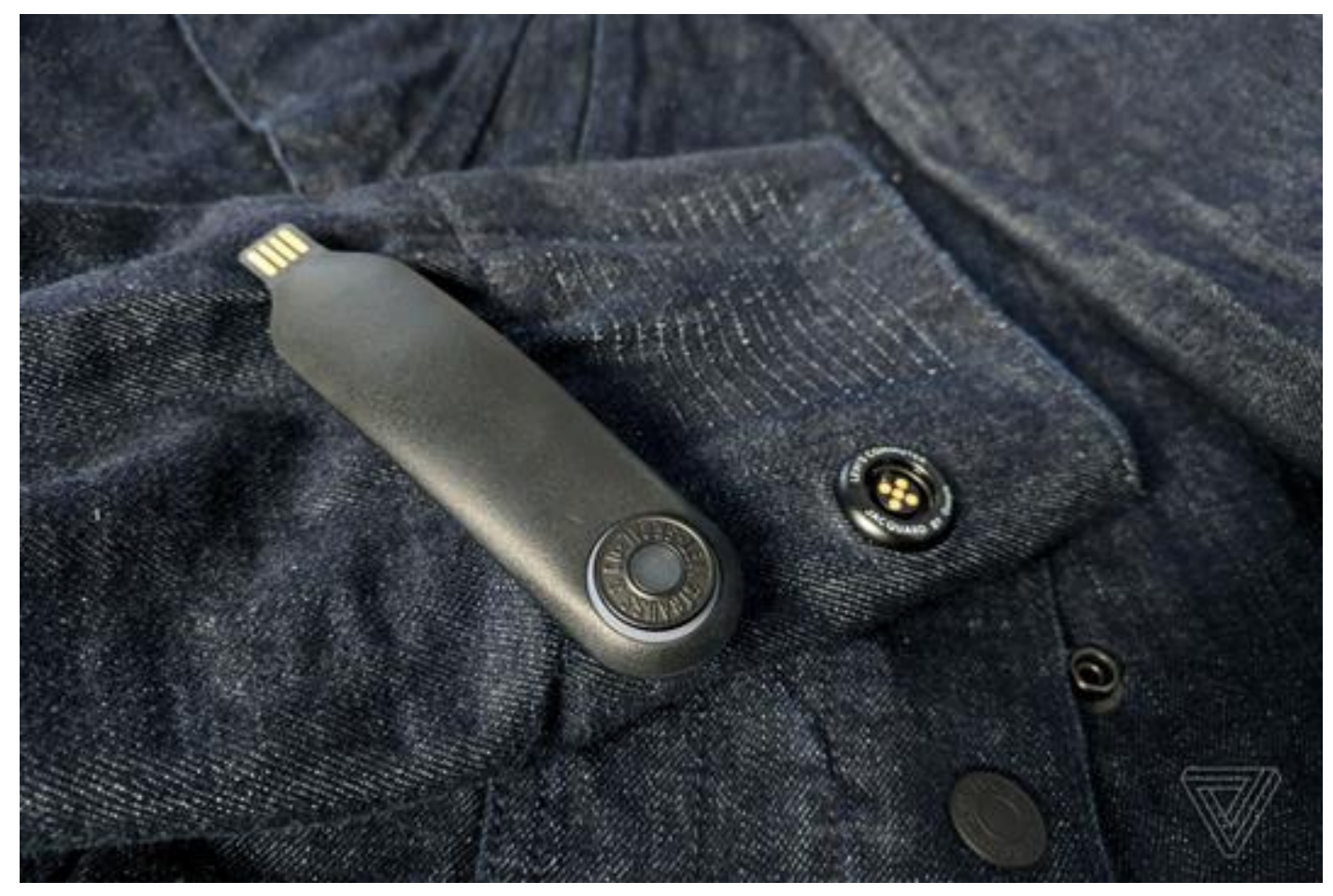

Figure 3. Levi's Commuter Jacket with Jacquard by Google (Levi's \& Google, 2017)

The next set of examples have more awareness of the environmental sustainability of e-textile products. Figure 4 presents the Closed Loop Smart Athleisure Fashion project by Marina Toeters at by-wire.net, Margreet de Kok at Holst Centre and Melissa Bonvie at Katoen Enzo. The authors designed a smart shirt which continuously measures the users' key vital signals based on Holst Centre's advanced flexible printed sensor technologies. An endlessly recyclable polyamide material Econyl is used. The business idea follows a closed-loop service system. In this case, the closed-loop plan is to collect the clothes back after the use and products along with parts are designed for the easy dismantling or reuse for a new product (Toeters, 2018).

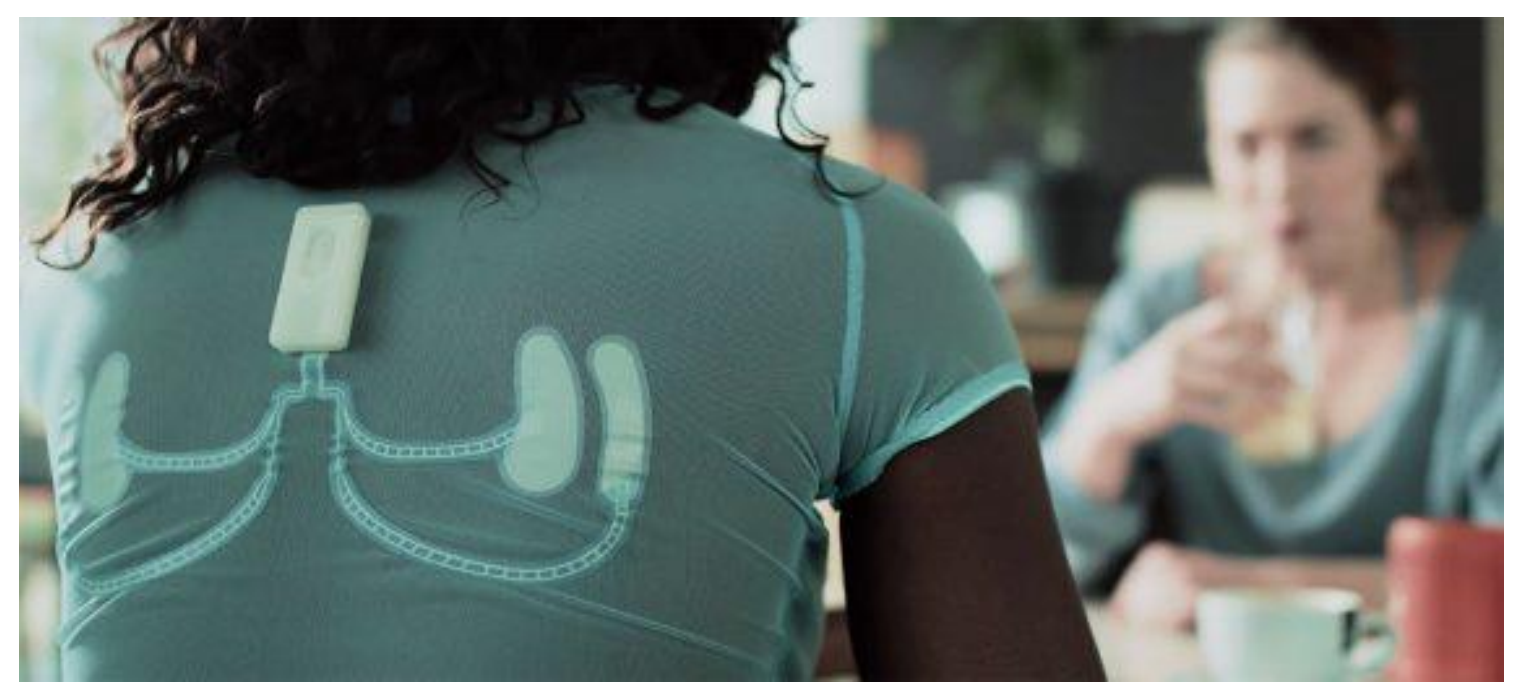

Figure 4. Closed Loop Smart Athleisure Fashion project by Marina Toeters at by-wire.net, Margreet de Kok at Holst Centre and Melissa Bonvie at Katoen Enzo (Toeters et al., 2017). 


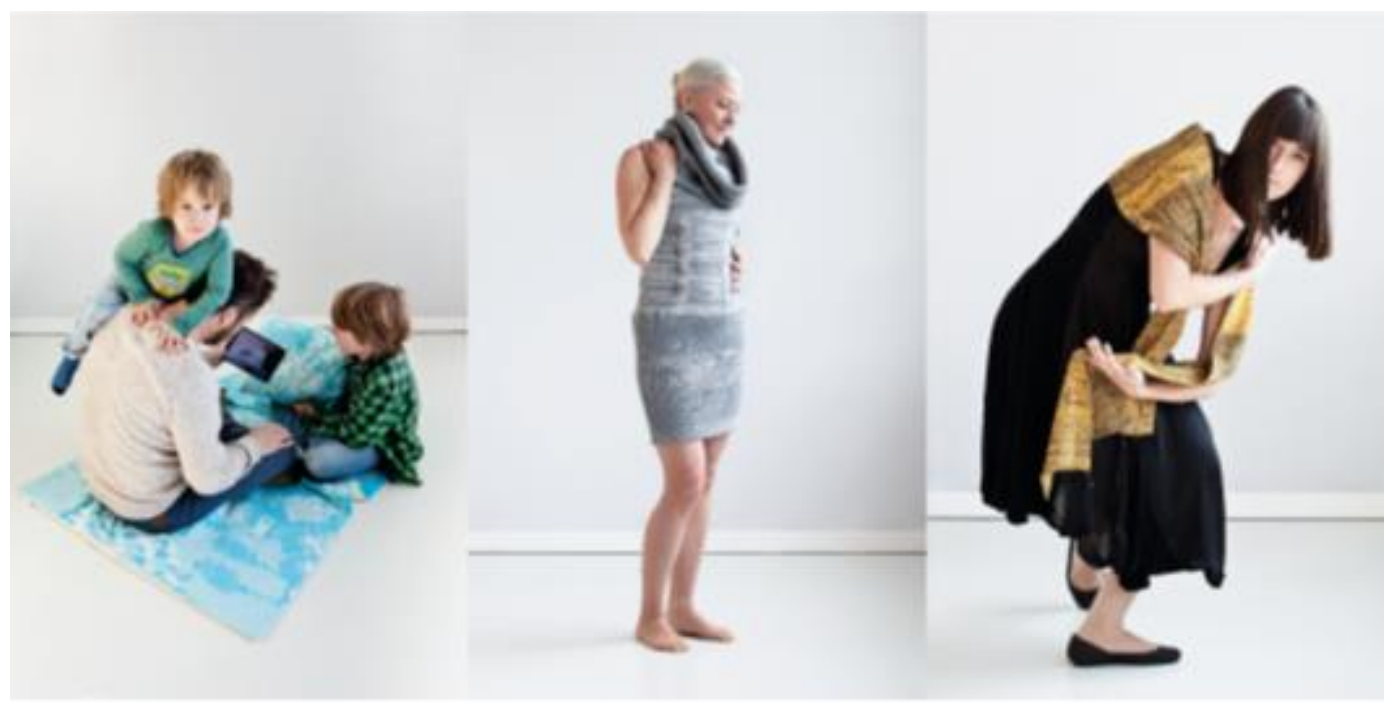

Figure 5. CRISP STS (Smart Textile Services) projects from left: the Bedtime Stories, Vibe-ing, Thermo Dance. Photos: Wetzer\&Berends (Kuusk et al., 2014)

Figure 5 shows CRISP STS (Creative Industry Scientific Programme Smart Textile Services) research projects (Kuusk et al., 2014). In the 2014 Ambience 14\&10i3m conference paper sustainability is discussed. The authors explored the limitations, e.g. not having to waste systems for e-textiles, and possibilities, e.g. service system opportunity to keep the product functioning for a longer time, while creating smart textile products and possible service systems.

The study aims to investigate the current stage in the discussion of e-textiles. This paper's objective is to discover the offered solutions and research to improve ecological impacts, bring out the gaps in current research and provide guidelines for the next steps in the area of end-of-life solutions to current e-textile market and research.

The main research questions are:

1) Is the research and development of end-of-life solutions in e-textiles undervalued?

2) What are the current possible solutions represented in the literature for e-textile products at their end-of-life stage?

3) What are the tools or methods in use to decrease the environmental impact from e-textiles?

4) What are the possible gaps or barriers in the development of e-textiles end-of-life solutions?

This paper begins by introducing the aim of the study and describing the methodology followed by results, findings and discussion chapter. The findings chapter analyzes the results more thoroughly and answers the research questions stated above. Discussion chapter provides further review on the topic and the possible need for future work.

\section{Methodology}

The studies reviewed in this paper were gathered via searches in academic databases in order to examine the state-of-the-art knowledge on e-textiles' sustainability from different research fields. Scopus, ScienceDirect and Web of Knowledge databases were first investigated, which yielded less than ten results 
after filtration. Therefore, it was decided to widen the database search to Google Scholar in order to find studies from sources that are not indexed (such as new journals devoted to emerging technology topics) and to remove some restrictions. The remaining restrictions were: the studies needed to be peer-reviewed, the papers needed to be in English and the main focus of the work had to be the sustainability issue for electronics based smart textiles. For example, Koo et al. (2014) researched design functions in transformable garments for sustainability. The work's aim was, however, to demonstrate how to transform clothing so the users would adopt sustainable behaviours. Because the focus was not on e-textiles but rather on user behaviour, it was left out of this review.

Restrictions did not include publishing time, place or type, which means book chapters, conference proceedings, dissertations and thesis and research papers were all accepted. The search terms and phrases used were: 'smart textiles sustainability', 'e-textiles sustainability', 'environmental risk prevention in smart textiles', 'end-of-life implications of e-textiles',' electronic textiles product lifetimes' and 'smart textiles environmental waste. Overall, this resulted in 73470 hits. The first one hundred publications were observed manually for relevance by reading titles, abstracts and results. The necessity of working through extensive amounts of data without a filtering option was the main disadvantage of the method and database.

Publications were found with searching terms combinations: smart textiles sustainability (Goncu-Berk, 2019; Köhler, 2013a, 2013b; Köhler et al., 2011; Köhler \& Som, 2014; Kuusk, 2016; Kuusk et al., 2014; Kuusk et al., 2012; Schischke et al., 2019; Ten Bhömer, 2016; Van der Velden et al., 2015 ; Wu \& Devendorf, 2020), e-textiles sustainability (Köhler, 2008), environmental risk prevention in smart textiles (Ossevoort, 2013), endof-life implications of e-textiles (McCann et al., 2005; Perry, 2017) electronic textiles product lifetimes (McLaren et al., 2017), smart textiles environmental waste (Timmins, 2009). Many publications surfaced under several search-terms, but they are presented in the order they were found.

\section{RESULTS}

From the search described in "Research Method" section, 18 relevant publications were chosen. Two publications were book chapters, four were conference proceedings, eight were journal articles, three dissertations and one Master thesis. Book chapters were from the books entitled Multidisciplinary Know-How for Smart-Textiles Developers and Smart Clothes and Wearable Technology. Conference proceedings were from Ambience 14\&10i3m (2014); Ninth IEEE International Symposium on Wearable Computers (2005) and PLATE: Product Lifetimes And The Environment (2017). Two journal articles were from Journal of Materials \& Design and others from Journal of Industrial Ecology, Journal of Technovation, International Journal of Fashion Design, Technology and Education, Nordic Textile Journal and Journal of Advances in Science and Technology.

Table 1 summarizes the review results. The topics of publications are divided into three main categories. The first group sees the smart textiles as a service approach as a solution for more sustainable smart textiles. The second category applies garment eco-design thinking principles in order to accelerate sustainable design and development. In the last category, the publications are aiming to increase awareness and share information about the issue. 
Table 1. Summarised review results. 18 publications are divided into 3 main categories. Authors, publication year, place and type together with specific reference and citation amount highlights the main findings

\begin{tabular}{|c|c|c|c|c|c|c|c|}
\hline $\mathrm{Nr}$ & Main result & Discussed by & Year & Place & Type & Ref & $\begin{array}{l}\text { Citation } \\
\text { amount }\end{array}$ \\
\hline 1 & \multirow{4}{*}{$\begin{array}{l}\text { Smart Textile } \\
\text { Services } \\
\text { (STS) }\end{array}$} & $\begin{array}{l}\text { K. Kuusk, O. Tomico, G. } \\
\text { Langereis,S. Wensveen }\end{array}$ & 2012 & $\begin{array}{l}\text { The } \\
\text { Netherlands }\end{array}$ & Article & $\begin{array}{l}\text { (Kuusk et al., } \\
\text { 2012) }\end{array}$ & 12 \\
\hline 2 & & $\begin{array}{l}\text { K. Kuusk, K. Niinimäki, S. } \\
\text { Wensveen, O. Tomico }\end{array}$ & 2014 & $\begin{array}{l}\text { The } \\
\text { Netherlands/ } \\
\text { Finland }\end{array}$ & Article & $\begin{array}{l}\text { (Kuusk et al. } \\
\underline{2014)}\end{array}$ & 3 \\
\hline 3 & & K. Kuusk & 2015 & $\begin{array}{l}\text { The } \\
\text { Netherlands }\end{array}$ & $\mathrm{PhD}$ dissertation & (Kuusk, 2016) & 11 \\
\hline 4 & & M. ten Bhömer & 2016 & $\begin{array}{l}\text { The } \\
\text { Netherlands }\end{array}$ & $\mathrm{PhD}$ dissertation & $\begin{array}{ll}\text { (Ten } & \text { Bhömer, } \\
\underline{2016)} & \end{array}$ & 8 \\
\hline 5 & \multirow{7}{*}{$\begin{array}{l}\text { Eco-design } \\
\text { strategy }\end{array}$} & A. R. Köhler & 2008 & Sweden & Master thesis & (Köhler, 2008) & 10 \\
\hline 6 & & $\begin{array}{l}\text { A. R. Köhler, L. M. Hilty, C. } \\
\text { Bakker }\end{array}$ & 2011 & $\begin{array}{l}\text { The } \\
\text { Netherlands/ } \\
\text { Switzerland }\end{array}$ & Article & $\begin{array}{l}\text { (Köhler et al. } \\
\underline{2011)}\end{array}$ & 70 \\
\hline 7 & & A. R. Köhler & 2013 & $\begin{array}{l}\text { The } \\
\text { Netherlands }\end{array}$ & Article & (Köhler, 2013b) & 37 \\
\hline 8 & & A. R. Köhler & 2013 & $\begin{array}{l}\text { The } \\
\text { Netherlands }\end{array}$ & $\mathrm{PhD}$ dissertation & (Köhler, 2013a) & 6 \\
\hline 9 & & A. R. Köhler, C. Som & 2014 & $\begin{array}{l}\text { The } \\
\text { Netherlands/ } \\
\text { Switzerland }\end{array}$ & Article & $\begin{array}{l}\text { (Köhler \& Som, } \\
\underline{2014)}\end{array}$ & 58 \\
\hline 10 & & $\begin{array}{l}\text { N. M. van der Velden, K. Kuusk, } \\
\text { A. R. Köhler }\end{array}$ & 2015 & $\begin{array}{l}\text { The } \\
\text { Netherlands/ } \\
\text { Germany }\end{array}$ & Article & $\begin{array}{l}\text { (Van der Velden } \\
\text { et al., 2015) }\end{array}$ & 32 \\
\hline 11 & & S. Wu, L. Devendorf & 2020 & USA & Conference proceedings & $\begin{array}{ll}\text { Wu } & \& \\
\text { Devendorf, } & \\
\underline{\text { 2020) }}\end{array}$ & 0 \\
\hline 12 & \multirow{7}{*}{$\begin{array}{l}\text { Educating, } \\
\text { guidelines }\end{array}$} & J. McCann, R. Hurford, A. Martin & 2005 & $\begin{array}{l}\text { United } \\
\text { Kingdom }\end{array}$ & Conference proceedings & $\begin{array}{l}\text { (McCann et al., } \\
\underline{2005)}\end{array}$ & 87 \\
\hline 13 & & M. Timmins & 2009 & $\begin{array}{l}\text { United } \\
\text { Kingdom }\end{array}$ & $\begin{array}{l}\text { Chapter in a book Smart } \\
\text { Clothes and Wearable } \\
\text { Technology }\end{array}$ & (Timmins, 2009) & $\begin{array}{l}4-\text { book } \\
25\end{array}$ \\
\hline 14 & & $\begin{array}{l}\text { A. McLaren, D.A. Hardy, T. } \\
\text { Hughes-Riley }\end{array}$ & 2017 & $\begin{array}{l}\text { United } \\
\text { Kingdom }\end{array}$ & Conference Proceedings & $\begin{array}{l}\text { (McLaren et al., } \\
\underline{2017)}\end{array}$ & 2 \\
\hline 15 & & A. Perry & 2017 & USA & Article & (Perry, 2017) & 2 \\
\hline 16 & & S. H. W. Ossevoort & 2013 & Switzerland & $\begin{array}{l}\text { Chapter in a book } \\
\text { Multidisciplinary Know-How } \\
\text { for } \quad \text { Smart-Textiles } \\
\text { Developers }\end{array}$ & $\frac{\text { (Ossevoort, }}{\underline{2013)}}$ & $\begin{array}{l}2-\text { book } \\
146\end{array}$ \\
\hline 17 & & $\begin{array}{l}\text { K. Schischke, N. F. Nissen, M. } \\
\text { Schneider-Ramelow }\end{array}$ & 2019 & Germany & Article & $\begin{array}{l}\text { (Schischke et al., } \\
\underline{\text { 2019) }}\end{array}$ & 1 \\
\hline 18 & & G. Goncu-Berk & 2019 & USA & Conference proceedings & $\begin{array}{l}\text { (Goncu-Berk, } \\
\underline{2019)}\end{array}$ & 0 \\
\hline
\end{tabular}




\section{Smart textile service system}

Smart Textile Services (STS) are considered as a value proposition, where smart textile products are part of larger service, and the profit is not only based on the sales of physical products (Toeters et al., 2013). STS requires a network of different partners, like the collaboration between technology, textile and service providers.

Kuusk et al. (2012) explore options to use smart clothing to increase the textile products' value overall to the users. By applying service systems and repair options, it is possible to develop and expand the connection between the garments and the users, thus creating more sustainable and long-lasting products.

Moving forward with the idea, Kuusk et al. (2014) emphasize the opportunity for more sustainable consumption through textile product service systems by combining product design with service elements. Authors bring out how this type of service system in textiles is not a new approach by bringing examples of leasing clothing and technical textile companies. For instance, Lindström is providing workwear, restaurant textiles, towels and mats as a service for their business-to-business clients. The paper highlights that the possibilities for STS lie on the personalized service aspect in order to extend the longevity of the product through making it more meaningful for the users. Thus also slowing down the consumption of these types of products. Moreover, the service system supports special care, durability and repurposing of e-textiles.

Kuusk (2016) presents the idea of STS as a solution to slow the consumption in her doctoral dissertation. The author created a link between intangible characteristics of craft qualities together with tangible product based sustainability qualities. The work proposes combining crafting and smart textiles to create meaningful products for achieving environmental and economic sustainability. While the work focuses more on meaningful creation, the application of smart textile services shows how circular product life-cycle would benefit on the products ecological end-of-life options.

Further on, STS and the Service Interfaces systems were evaluated via a set of garment prototypes in the real environment in the dissertation by Ten Bhömer (2016). The evaluation was performed within the eldercare company by involving family members and direct end-users. The care provider selected the styles for the testing process from prototype collection. The testing consisted of the product training, observations in the use period, repairing and washing the product. In order to release STS, the tight connection between digital data and the user in the context and social environment of the application are apparent. The work demonstrated clearly how the STS provides an option of constant product support for the users and would be an acceptable way to create a circular life-cycle also for e-textiles.

The next chapter moves on to discuss the possibilities to increase environmental sustainability already in the design phase.

\section{Eco-design strategy}

The product recyclability needs to be considered originally in the design phase. Eco-design is a design approach, considering the environmental impacts of the product during its whole life cycle (Cimatti et al., 2017; Van der Velden et al., 2015). The approach comprises the integration of environmental aspects of technology development and product design.

Köhler (2008) indicates the unpredictability and complexity of the post-consumer e-textiles waste amount could cause challenges for recycling. The waste and recycling methods are highly dependable on the 
application area, design and construction of e-textiles, as well as consumer's awareness on waste separation. Hence, the procedures for recycling are truly undeveloped. The wide range of application areas for e-textiles are found from medical and health care, sports and fashion, interior and furniture, as well the automotive and construction industry, which unquestionably leads to several waste streams. The author also presents the current three principles for the end consumer for disposing of e-textiles: down cycling at home (using textile parts), recycling as electronic waste or recycling as an old textile product. International levels of waste stream systems are, however, irregular and e-textiles, as being in a multidisciplinary field, is hindering one system implementation.

Köhler (2008) discusses in his thesis' further on the eco-design strategy to prevent future end-of-life problems of merging technologies. New practises meeting specific properties of e-textiles are needed. The author also addresses the strategy in the 2013 paper stating that waste prevention is more important than the recycling aspect in the product design. Designers should prolong the useful life of e-textiles, holding off their obsolescence. This could be achieved by designing products for repair, refurbishment and reuse. Thus, choosing waste prevention over recycling. The reusing and repair reduce the consumption from primary resources. In some cases, the textile materials can replace moulded plastics, such as plastic covers in electronic products. In the same paper, Köhler also brings out 3 waste preventative eco-design approaches, including labelling, e.g. with RFID or QR codes, for easier sorting of products.

Likewise, Köhler et al. (2011) emphasize how good integration design is essential, and it is not reasonable to expect good recycling systems fast. Seamless integration is interesting to thrive for, however, it should be reviewed with care since it makes recycling extremely difficult.

The lack of standardization on smart textiles is noteworthy. Technical Report 16298:2011 by European Committee of Standardization (CEN) has been released. However, it is not a standard but an informative document that provides only for standardization work (CEN, 2011). Concerns about the lack of regulations are again mentioned by Köhler (2013a) and recommend to improve the coherence in waste policies with the eco-design strategy in national and the European level. The policy harmonisation needs to add a technical perspective of different e-textile products to eco-design thinking.

Köhler and Som (2014) also emphasize in their work how clear legislation is imperative to make smart textiles sustainable. Moreover, they bring out the importance of eco-design principles implementation in the product creation phase since the redesign of existing products can be costly. Eco-design principles could be used as risk mitigation in the design phase. The authors also offer an idea that smart textile developers could make an open-source LCA database that would help with eco-design principles in the design phase and overall improve end-of-life options for e-textiles.

Van der Velden et al. (2015) present redesigned products by applying the results of the LCA (life-cycle assessment) and the eco-design approach. The hypothesis of the work was that redesigning according to eco-design principles, the eco-costs will improve by $25 \%$ (product lifetime was improved by $50 \%$ ), which was proved right. The research found that conscious material selection, such as the decision to apply acrylic instead of merino wool because the eco-costs for producing acrylic are $80 \%$ of producing merino wool. However, the microplastics of acrylic fibres are not considered in the study. The copper conductive wire instead of silver reduced $1,4 \%$ of eco-costs, but the functionality stayed the same. Overall, it was proved that implementing eco-design strategy, product lifetime was extended, and waste decreased by decreasing material consumption or integration design.

Wu and Devendorf (2020) do not concentrate on eco-design specifically. However, their study investigates how computational design can support designing-for-disassembly. The authors don't just explore separating 
electronics from textile, but unravelling the whole garments and then reusing all materials, e.g. the yarn. Throughout the work process, the authors made hardware modifications to the textile loom machinery and software modifications in the CAD system to support the disassembly process and make it efficient. This approach supports also separating conductive yarn, thread and textiles at the end-of-life phase.

\section{Educating and developing the awareness}

Literature also included options for a more broad approach to the topic. McCann et al. (2005) brought out a gap between the designers and the potential market. It is hindered by the lack of common language to understand the disparate mix of aesthetic, technical and cultural needs for smart clothing. Authors emphasized the clear and comprehensive understanding of user needs and requirements prior to embarking on the research and development of smart clothing. It is essential to create valuable and long-lasting products since users themselves decide how they will take care of the product. The paper mentions the aim of the design team should be to obtain maximum technical performance while not compromising with bigger environmental impact. Thus, the authors see the need for a design tool to guide the smart clothing creation by including end-of-life implications.

Similarly to McLaren et al. (2017) and Perry (2017) emphasizes that the lack of knowledge and specific education among creators, leading to limited concerns and solutions for disposal issues of smart clothing. Perry suggests that educational programs should be tailored as multidisciplinary courses; including material/fibre science, electronic engineering, functional apparel, eco-design, for instance. An in-depth study was conducted to have a current overview of researchers and industry workers mind-set on the topic,. The study involved topics like disposal of electronics, separation, consumer, industry and designer responsibility. The results indicated how only 2 out of 18 mentioned strategies for e-textiles disposal issues which shows an immense gap in knowledge on the topic.

Likewise, McLaren et al. (2017) state that ensuring knowledge and understanding of sustainability across design and production will be imperative, alongside supporting sustainable consumer behaviour during use, care and end of life. The authors' aim was to build-up a workshop for educating on lifetimes of e-textiles. Crucial points were identifying collaborations together with challenges and opportunities of sustainable smart textiles.

Background on e-waste and universal guidelines for designing smart clothes and wearable technology is written up by Timmins (2009). One of the author's suggestions is to perform two actions in designing smart clothes and wearable technology (SCWT): improving the knowledge of fibre and fabric materials including environmental and social aspects in manufacturing processes, and planning of end-of-life consideration for the item instantly in the initial design phase. He encourages to speed up the emerging waste disposal legislation, to seek reassurance from suppliers and importers about compliance in terms of RoHS.

Timmins also brings out the fact that regular garments also include several non-textile parts, e.g. zippers or drawcords. Thus, they are not much different from e-textile products that include extra materials. However, it is also highlighted that smart clothing usually includes great amounts of metals, and the integration level is a big part of defining the end-of-life options. That is when the design is essential and is the main contributor to efficient and realizable end-of-life solutions.

An essential part of user involvement is talked about by Ossevoort (2013). The author highlights the user's involvement in every stage of the design process, which leads to producing a more desirable product and thus satisfies the user longer. Book chapter goes through different design phases and questions by changing 
their aspect and involving the end-user. In the end, the author created a list of general guidelines to consider while making smart textile products. The main point for ecological end-of-life solution is to design for disassembly, which has been the main point also with previous studies.

Schischke et al. (2019) based their study on wearable, flexible and conformal electronics. While authors presented many examples from non-textile related products or prototypes, the e-textiles were still a vital part of the article. The authors suggest "green design rules" which propose to plan for realistic end-of-life scenarios, among other suggestions, e.g. designing with biodegradable materials.

Goncu-Berk (2019), on the other hand, made an overview focusing on textile aspects and including less electronics point-of-view. The author states that the future of sustainability in the smart textiles field needs a systematic approach and depends on the sustainability of its components and their lifespan. While no specific solutions for end-of-life issues for e-textiles are presented, the author brings out a clear need for it since these products will intensify the textiles waste management issues.

While overall education and guidelines for more sustainable e-textiles are available in the literature, the main topic is involving end-users and using specific design methods to reach the goal.

\section{Findings}

The first question aimed to find out whether the end-of-life solutions for e-textile products research and development field was undervalued. While there were many publications matching the keywords, such as 'end-of-life implications of e-textiles' or' electronic textiles product lifetimes', the specific solutions to the endof-life issues in e-textile products were still in low amounts. Only 18 very specific publications that mainly focused only on the issue were found.

The second research question focused on the current possible solutions in the literature for e-textile products at their end-of-life stage. We can state the lack of clear solutions, and the best practices in the area. However, the publications can be divided into three solution tracks for end-of-life issues: (1) publications about STS, (2) publications about the eco-design concept for smart textile product design, and (3) publications about general education on e-textiles sustainability or creating guidelines on the topic.

The first track found in the review process to decrease environmental impacts of e-textiles was Smart Textile Services (STS) system where smart textile products are part of the service system, and the profit mainly comes from renting the products (Toeters et al., 2013). STS approach could disrupt the excess amount of clothing consumption (Kuusk, 2016). This concept creates an opportunity to minimize the gap by creating more personalized products according to user needs and by that increase the longevity of products (Kuusk et al., 2014). Together, these studies demonstrate how STS can support ecological and circular end-of-life solutions for e-textiles.

The second track proposes the eco-design concept also for smart textile product design. The approach supports the integration of environmental aspects and product design, e.g. promoting design-for-disassembly. The eco-design principles could be the foundation for standardization and rules for making environmentallyfriendly e-textiles. The concept could be used in open-source platforms (Köhler \& Som, 2014) or just as a method for redesigning more ecological e-textiles (Van der Velden et al., 2015).

Both of the first possible solutions are a part of the circular economy system's second principle. STS specifically supports the three key actions for the sustainability of the fashion and textiles field proposed by 
The Ellen MacArthur Foundation. Eco-design, more particularly designing-for-reuse could help e-textiles to keep products in use for longer times and save in materials costs.

The last topic group was the broadest and covered the third research question by bringing out different tools and methods, e.g. design tool (McCann et al., 2005) or guidelines (Ossevoort, 2013), for supporting end-oflife solutions.

Needless to say, the topic variation could be larger and more diverse. Thus, we found some gaps and barriers in the development of end-of-life of e-textiles. For example, materials separation and knowledge of materials waste management in e-textiles are partial. Although guidelines for ecological e-textiles are offered in several presented publications, official standards and legislation are still lacking. While the eco-design strategy is widely known and even standardized for companies to implement, the e-textiles production has not recognized it fully. The recycling of conductive yarns, fabrics or fibres is not mentioned. Only Reuse of yarns is offered by Wu and Devendorf (2020).

The 18 publications covered here were written by 25 different authors, while Köhler was the leading or one of the authors in 5 publications, Kuusk in 3 publications.

Citation amount was checked from Google Scholar and Semantic Scholar. As expected, book chapters themselves, dissertations and the Master thesis had limited direct citations, mainly between 2-10. Most citations were from McCann et al. (2005) conference paper, which was also one of the oldest sources used.

The era of smart textiles and wearable technology starts with the 1990s. However, the publication year of the studies examined reveals a relatively recent focus on sustainability in smart textiles. The first publication was constructed no sooner than 2005 and most of them were published after 2010. Publication year also indicates the pace is clearly accelerating. Noteworthy is that 15 out of 18 of the research studies found were conducted in Europe. That result indicates that the issue is recognised only in one part of the world, even though the smart textile product development takes place globally.

Therefore, only a small amount of research has been done on finding ecological solutions for e-textile making, production and after-life solutions. While the ecological aspect gathers increasing attention in the world, the main focus in e-textiles is still at a technological level. Research is only done by a small group of researchers and mainly in Europe. This observation supports the notion brought out in the introduction: most research focuses on innovations of different e-textile fabrication techniques and materials.

Predominantly, articles and conference proceedings lead innovative ideas, whereas the dissertations also provide in-depth practical showcases and solutions. The number of citations varies. Most cited paper is from McCann et al. (2005), which is also the oldest paper published. Least cited papers are from Wu and Devendorf (2020) and Goncu-Berk (2019) which are the most recent studies. Köhler, who frequently is the most represented and cited in the results.

Central themes presented are meaningful creation by also building a relationship between users and e-textile products. Design for repair and reuse together with design-for-disassembly is repeatedly introduced in all three groups. STS offers practical circular life-cycle solutions and extending the longevity of e-textiles by not offering just a product but a service (Kuusk et al., 2012). Utilizing LCA method in design-phase is also presented as an option to improve end-of-life issues by even offering to create an open-source database that would support eco-design principles with LCA information (Köhler \& Som, 2014; Van der Velden et al., 2015). Lack of knowledge for designing for disassembly and efficient end-of-life solutions is excessively discussed together with omitting the user's needs during the design phase (McCann et al., 2005; McLaren et al., 2017; 
Ossevoort, 2013; Perry, 2017; Timmins, 2009). Improving the knowledge of materials environmental impact and planning for end-of-life solutions would benefit the field tremendously.

Based on observations the design phase is the most critical for the whole future of the product and its environmental impact. E-textiles vary based on different aspects, such as user groups and application areas. Every option needs to be considered and evaluated. Several questions, such as materials separation and standards availability, remain currently unanswered. Future studies on the current topic are highly recommended.

\section{DISCUSSIONS}

It was observed that little research focuses on e-textiles end-of-life solutions. While some reports from EU funded projects, such as Worth Projects and WearSustain (COSME Programme of the European Union, 2017-2020; Horizon 2020 Work Programme, 2017-2018) are supporting innovations to resolve sustainability issues, only three general approaches were found: (1) Smart Textile Services, (2) Eco-Design strategy and (3) a more broad approach for creation of guidelines and educating on the topic.

The research terms used generated over 70000 results. The keywords used brought up publications that also discussed sustainability in wider and/or different forms that were intended in this review. For example, Walser et al. (2011) papers are about conducting LCA for T-shirts that are treated with nanosilver particles, thus there is no relation to e-textiles. Instead, in Page (2015) paper, sustainability is discussed briefly in the literature overview part and mentioned again for possible future research options. These examples illustrate a variety of discussions within the same search terms. Thus, the finding of relevant publications necessarily requires comprehensive manual filtering work.

Possible changes in technology, such as increased use of nanotechnology in electronics or artificial reality with clothing, have not been considered in this study. These could possibly both increase or decrease the level of recycling. However, since these options have not been developed far enough to consider in the current situation.

Recycling technologies need to develop further at a faster pace. Karell and Niinimäki (2019) bring out how separation for textile waste is still mainly manual. The method is highly problematic because of its inaccuracy and inefficiency. Blended fabrics and fibres separation technology are still underdeveloped. The Trash-2Cash project demonstrated that solid-state NMR (nuclear magnetic resonance) allows to determine cellulose and polyester fibres in both pre-consumer and post-consumer waste textiles, but it is only a start (Haslinger et al., 2019).

Still, the gaps in current research are still obvious. The study points out a considerable gap in the recycling of conductive textile materials, fabrics covered or embedded with conductive components, such as metal or polymer. Köhler (2008) highlights the uncertainty of conductive material specifications. In literature, the electrical conductivity is mentioned, although the amount of metal content in the product is excluded. This uncertainty might become an obstacle for the commercialization of smart textile applications.

Lack of common language between designers, industry and end-users is also highlighted. Moreover, since e-textiles combine several different fields, e.g. electronics, textiles and ICT (information and communications technology), the knowledge to combine these sections into ecological and efficient manufacturing is problematic. Closing the gap with proper design-tools, workshops or education programs could provide a solution (Larsson et al., 2018; McCann et al., 2005; McLaren et al., 2017). 
Alternatives for material selection and processing methods as well as materials recycling methods are available. However, the information is scattered, and the focus is on separate materials but not on the full system. Thus, the smart textile sector is in desperate need of standards and regulations for the cradle to cradle life-cycle. Unifying the field with correct standardization and unambiguous guidelines is necessary. The next focal points could be recycling different smart textiles, managing the waste streams as well as the dividing specific responsibilities of each party in the product value chain from design to recycling.

These findings suggest to take preventative actions urgently, rather than redo the process later. First measures should include implementing smart textiles waste management to existing environment-focused framework or standards, such as WEEE (Waste Electrical and Electronic Equipment Directive by European Commission (European Parliament and Council, 2012) and RoHS (Restriction of Hazardous Substances Directive by European Commission (European Parliament and Council, 2011), or create new regulations.

It is possible to hypothesise that without changes, the e-textiles market will suffer more extensively in the future. The upcoming regulations might hinder the commercialization process of developed product innovations. In addition, lack of regulations decreases the willingness of the companies to research, develop and produce e-textile based products which obviously hinders the innovations in the area.

Further studies and development for environmentally sustainable solutions for smart textiles are needed. The end-of-life considerations including materials recyclability, sustainable manufacturing methods and techniques should initially dominate the smart textiles designing process. It is necessary to recognize that lower environmental impact e-textiles development would have global interest. Future research questions may also include what are the possibilities if the sustainability issues will be incorporated more widely now and taken into account during innovations. Positive outcomes and benefits to integrating sustainability mindset may be far greater compared to not taking the necessary steps.

\section{CONCLUSIONS}

Several innovations in the e-textile field are ongoing whether smart elements are on fibre level or integrated later. For example, the process for the recycling of smart textiles with conductive parts on yarn-level (Levi's \& Google, 2017) or laminated on the product could be very different (Toeters et al., 2013). Based on the level of difficulty of electronics and textile waste management, electronic textiles possible waste systems need urgent attention.

One of the aims of the current study was to identify gaps in current research. The results indicated that most of the research is centred in Europe and has a very limited group of practitioners. It can be argued that the main focus in research is still on the innovations of conductive materials and the fabrication of e-textiles. Lack of information in the environmental sustainability of smart textiles shows an extensive gap in the research since there is a substantial amount of studies about smart textile product development and integration technologies. The lack of standardization causes the designing and life-cycle thinking of different smart textile products vastly challenging. European Committee of Standardization (CEN) has published Technical Report 16298:2011 (CEN, 2011). Nevertheless, it is not an official standard but an informative document that provides information on the technical content of standardization work. The literature offers several "green" guidelines for designing ecological e-textiles, but the regulations are still missing.

Firstly, the study sets out the possible approaches proposed in the literature for e-textiles environmental sustainability. The publications could be divided into three categories based on their content and aims. In the 
first category, the focus was on lowering the environmental impact of smart textiles by the smart textile product service systems (STS), where profit is not only based on the sales of physical products (Toeters et al., 2013). This way the products would have a longer lifetime and producers take full responsibility for recycling after use. STS requires a network of different partners, from textile and technology fields, and service providers to collaborate in an open environment (Ten Bhömer, 2016; Toeters et al., 2013).

The second category concentrates on the environmental aspects initially from the design phase of the product by applying the eco-design strategy. Sustainable design concepts for e-textiles ought to prioritise waste prevention over recycling (Köhler, 2013a). Köhler et al. (2011) emphasize that industrial designers have a vital role by creating showcases of sustainable e-textiles. The European Ecodesign directive ("Directive 2009/125/EC," 2009) could also serve as a model since it mandates eco-design requirements for the development of energy-related products.

The third publications group proposed to focus a step before the design phase. Publications suggested educational programs to be tailored as multidisciplinary courses, to increase knowledge level among creators which leads to improved applications for disposal issues of smart textiles and clothing. Design tools and general guidelines were additionally offered for ecological e-textile creation.

The field of e-textiles needs extensive studies and developments for the creation of environmentally sustainable solutions. The research on the topic should become a focus worldwide. The legislation should be developed similarly globally. Next step should be the creation of guidelines for smart textile waste management and environmental obligations for design and development. Finally, it is essential to determine the regulations for the whole life-cycle of smart textiles.

\section{Acknowledgements}

We thank Dr Cindy Kohtala, postdoctoral researcher in the Department of Design at Aalto University for contribution to methodology part that greatly improved the manuscript.

\section{References}

Beton, A., Dias, D., Farrant, L., Gibon, T., Guern, Y. I., Desaxce, M., . . Dodd, N. P. (2014). Environmental Improvement Potential of textiles (IMPRO Textiles).

Carvalho, H., Catarino, A. P., Rocha, A., \& Postolache, O. (2014, 11-12 June 2014). Health monitoring using textile sensors and electrodes: An overview and integration of technologies. Paper presented at the 2014 IEEE International Symposium on Medical Measurements and Applications (MeMeA).

Castrillón, R., Pérez, J. J., \& Andrade-Caicedo, H. (2018). Electrical performance of PEDOT:PSS-based textile electrodes for wearable ECG monitoring: a comparative study. BioMedical Engineering OnLine, 17(1), 38. doi: 10.1186/s12938-018-0469-5

CEN. (2011). CEN/TR 16298:2011: European Committee of Standardization.

Cimatti, B., Campana, G., \& Carluccio, L. (2017). Eco Design and Sustainable Manufacturing in Fashion: A Case Study in the Luxury Personal Accessories Industry. Procedia Manufacturing, 8, 393-400. doi: https://doi.org/10.1016/j.promfg.2017.02.050

Copyright () Ellen MacArthur Foundation. (2017). A New Textiles Economy: Redesigning fashion's future (pp. 6): The Ellen MacArthur Foundation

COSME Programme of the European Union. (2017-2020). WORTH Project: COSME Programme of the European Union.

DG CONNECT. (2017). Smart textiles, flexible \& wearable electronics: FP7 Projects Portfolio analysis: European Commission, Directorate Digital Industry.

Directive 2009/125/EC (2009). 
Duque Ciceri, N., Garetti, M., \& Sperandio, S. (2010, 2010//). From Product End-of-Life Sustainable Considerations to Design Management. Paper presented at the Advances in Production Management Systems. New Challenges, New Approaches, Berlin, Heidelberg.

EN ISO 14006. (2011) Environmental Management Systems - Guidelines for Incorporating Eco-design. Brussels.

European Commission. (2016). Smart Wearables: Reflection and Orientation Paper. Brussels, Belgium.

European Environment Agency. (2019). Textiles in Europe's circular economy.

Restriction of Hazardous Substances in Electrical and Electronic Equipment (RoHS) Directive 2011/65/EU (2011).

Waste Electrical \& Electronic Equipment (WEEE) Directive 2012/19/EU (2012).

Ferraro, V. (2015). Smart Textiles and Wearable Technologies for Sportswear: A Design approach. https://www.scilit.net/articlea4bb86b6f47fd43f17ceccaba4f2437f

Glazkova, N., Podladchikova, T., Gerzer, R., \& Stepanova, D. (2020). Non-invasive wearable ECG-patch system for astronauts and patients on Earth. Acta Astronautica, 166, 613-618. doi: https://doi.org/10.1016/j.actaastro.2019.01.036

Goncu-Berk, G. (2019). Smart Textiles and Clothing: An Opportunity or a Threat for Sustainability? Paper presented at the Textile Intersections 2019, London, UK. https://repository.Iboro.ac.uk/articles/conference_contribution/Smart_Textiles_and_Clothing_An_Op portunity_or_a_Threat_for_Sustainability_/9724619

Haslinger, S., Hietala, S., Hummel, M., Maunu, S. L., \& Sixta, H. (2019). Solid-state NMR method for the quantification of cellulose and polyester in textile blends. Carbohydrate Polymers, 207, 11-16. doi: https://doi.org/10.1016/j.carbpol.2018.11.052

Horizon 2020 Work Programme. (2017-2018). WearSustain: European Union.

Hou, T.-C., Yang, Y., Zhang, H., Chen, J., Chen, L.-J., \& Lin Wang, Z. (2013). Triboelectric nanogenerator built inside shoe insole for harvesting walking energy. Nano Energy, 2(5), 856-862. doi: https://doi.org/10.1016/j.nanoen.2013.03.001

Hu, Y., \& Zheng, Z. (2019). Progress in textile-based triboelectric nanogenerators for smart fabrics. Nano Energy, 56, 16-24. doi: https://doi.org/10.1016/j.nanoen.2018.11.025

Ilen, E. (2015). Decontamination of Wearable Textile Electrodes for Medical and Health Care Applications. Tampere: Tampere University of Technology.

Karell, E., \& Niinimäki, K. (2019). Addressing the Dialogue between Design, Sorting and Recycling in a Circular Economy. The Design Journal, 22(sup1), 997-1013. doi: 10.1080/14606925.2019.1595413

Katashev, A., Okss, A., Krüger-Ziolek, S., Schullcke, B., \& Möller, K. (2019, 2019//). Application of GarmentEmbedded Textile Electrodes for EIT Based Respiratory Monitoring. Paper presented at the World Congress on Medical Physics and Biomedical Engineering 2018, Singapore.

Köhler, A. (2008). End-of-life implications of electronic textiles - Assessment of a converging technology.

Köhler, A. (2013a). Anticipatory Eco-Design Strategies for Smart Textiles Perspectives on environmental risk prevention in the development of an emerging technology.

Köhler, A. (2013b). Challenges for eco-design of emerging technologies: The case of electronic textiles. Materials \& Design, 51, 51-60. doi: https://doi.org/10.1016/j.matdes.2013.04.012

Köhler, A., Hilty, L., \& Bakker, C. A. (2011). Prospective Impacts of Electronic Textiles on Recycling and Disposal. Journal of Industrial Ecology, 15, 496-511. doi: 10.1111/j.1530-9290.2011.00358.x

Köhler, A., \& Som, C. (2014). Risk preventative innovation strategies for emerging technologies the cases of nano-textiles and smart textiles. Technovation, 34(8), 420-430. doi: https://doi.org/10.1016/j.technovation.2013.07.002

Koo, H. S., Dunne, L., \& Bye, E. (2014). Design functions in transformable garments for sustainability. International Journal of Fashion Design, Technology and Education, 7(1), 10-20. doi: 10.1080/17543266.2013.845250

Kuusk, K. (2016). Crafting sustainable smart textile services.

Kuusk, K., Niinimäki, K., Wensveen, S., \& Tomico, O. (2014). Smart Textile Products and Services in Sustainability Context. Paper presented at the Ambience 14\&10i3m, Scientific Conference for Smart and Functional Textiles, Well-Being, Thermal Comfort in Clothing, Design, Thermal Manikins and Modelling, Tampere.

Kuusk, K., Tomico, O., Langereis, G., \& Wensveen, S. (2012). Crafting Smart Textiles : a meaningful way towards societal sustainability in the fashion field? Nordic Textile Journal, 1(6-15). 
Larsson, J., Vellesalu, A., Milano, P. d., Cappellieri, A., Colombi, C., Tenuta, L., . . Miller, G. (2018). FashionTech, Education and Research Benchmarching Report: University of Borås, Swedish School of Textiles, Politecnico di Milano, Dipartimento di Design, University of the Arts London, London College of Fashion.

Levi's, \& Google. (2017). Levi's Commuter Jacket with Jacquard by Google. Retrieved 13 Feb, 2020, from https://atap.google.com/jacquard/about/

McCann, J., Hurford, R., \& Martin, A. (2005, 18-21 Oct. 2005). A design process for the development of innovative smart clothing that addresses end-user needs from technical, functional, aesthetic and cultural view points. Paper presented at the Ninth IEEE International Symposium on Wearable Computers (ISWC'05).

McLaren, A., Hardy, D. A., \& Hughes-Riley, T. (2017). Electronic textiles and product lifetimes: exploring design strategies for product longevity. Paper presented at the Research in Design Series.

Nørup, N., Pihl, K., Damgaard, A., \& Scheutz, C. (2018). Development and testing of a sorting and quality assessment method for textile waste. Waste Management, 79, 8-21. doi: https://doi.org/10.1016/j.wasman.2018.07.008

Ossevoort, S. H. W. (2013). 14 - Improving the sustainability of smart textiles. In T. Kirstein (Ed.), Multidisciplinary Know-How for Smart-Textiles Developers (pp. 399-419): Woodhead Publishing.

Page, T. (2015). Embedded Electronics in Textiles and Wearable Technology. i-Manager's Journal on Embedded Systems, 3(4), 1-18.

Paul, G., Torah, R., Beeby, S., \& Tudor, J. (2015). Novel active electrodes for ECG monitoring on woven textiles fabricated by screen and stencil printing. Sensors and Actuators A: Physical, 221, 60-66. doi: https://doi.org/10.1016/j.sna.2014.10.030

Perry, A. (2017). Exploring from creators' perspectives issues and solutions about knowledge, difficulties, and disposal in making smart clothing designs. International Journal of Fashion Design, Technology and Education, 11(1), 129-137. doi: 10.1080/17543266.2017.1332246

Ruck, A. (2015). Information and Stakeholders' Day on Wearables. Brussles, Belgium: European Commission.

Sanyé-Mengual, E., Lozano, R., Farreny, R., Oliver-Solà, J., Gasol, C., \& Rieradevall, J. (2014). Introduction to the Eco-Design Methodology and the Role of Product Carbon Footprint. In S. S. Muthu (Ed.), Assessment of carbon footprint in different industrial sectors (Vol. 1, pp. 1-24): Springe.

Schischke, K., Nissen, N. F., \& Schneider-Ramelow, M. (2019). Flexible, stretchable, conformal electronics, and smart textiles: environmental life cycle considerations for emerging applications. MRS Communications, 10(1), 69-82. doi: 10.1557/mrc.2019.157

Schneegass, S., \& Amft, O. (2017). Smart Textiles: Fundamentals, Design, and Interaction: Springer, Cham. SmartX. (2019). The SmartX Accelerator Programme is launched [Press release]

Stoppa, M., \& Chiolerio, A. (2014). Wearable electronics and smart textiles: a critical review. Sensors (Basel, Switzerland), 14(7), 11957-11992. doi: 10.3390/s140711957

Suunto. (2019). Suunto Movesense Sports Bra with integrated textile electrodes for heart rate monitoring. Retrieved 13.02, 2019, from https://www.movesense.com/product/movesense-sportsbra/?fbclid=IwAR3KwFLEkBsRaOTyc8YtgMB-0gugBSle46uyxOce-SwaLBCm7I3Oa1WBHDc

Ten Bhömer, M. (2016). Designing embodied smart textile services: The role of prototypes for project, community and stakeholders.

Timmins, M. (2009). 16 - Environmental and waste issues concerning the production of smart clothes and wearable technology. In J. McCann \& D. Bryson (Eds.), Smart Clothes and Wearable Technology (pp. 319-331): Woodhead Publishing.

Toeters, M. (2018). Closed Loop Smart Athleisure Fashion. Retrieved May 27 2019, from www.bywire.net/clsaf/

Toeters, M., de Kok, M., Bonvie, M., \& Enzo, K. (2017). Closed Loop Smart Athleisure Fashion project. Retrieved 13.02.19, from http://www.by-wire.net/wear-sustain-closed-loop-smart-atheleisure-fashion/

Toeters, M., Ten Bhömer, M., Bottenberg, E., Tomico, O., \& Brinks, G. (2013). Research through Design: A Way to Drive Innovative Solutions in the Field of Smart Textiles. Advances in Science and Technology, 80, 112-117. doi: 10.4028/www.scientific.net/AST.80.112

Van der Velden, N. M., Kuusk, K., \& Köhler, A. (2015). Life cycle assessment and eco-design of smart textiles: The importance of material selection demonstrated through e-textile product redesign. Materials \& Design, 84, 313-324. doi: https://doi.org/10.1016/j.matdes.2015.06.129 
Van Langenhove, L., \& Hertleer, C. (2004). Smart clothing: a new life. International Journal of Clothing Science and Technology, 16(1/2), 63-72. doi: 10.1108/09556220410520360

Vercruysse, N. (2015). Strategic Foresight: Towards the 3rd Strategic Programme of Horizon 2020: European Commission.

Walser, T., Demou, E., Lang, D. J., \& Hellweg, S. (2011). Prospective Environmental Life Cycle Assessment of Nanosilver T-Shirts. Environmental Science \& Technology, 45(10), 4570-4578. doi: 10.1021/es2001248

WEAR Sustain. (2018). An Aesthetic, Ethical and Critical Approach to Wearable Technologies, Smart and Etextile Developement: A Two Year Innovation Action Study [2017-2018] (pp. 1-21).

Wu, S., \& Devendorf, L. (2020). Unfabricate: Designing Smart Textiles for Disassembly. Paper presented at the Proceedings of the $2020 \mathrm{CHI}$ Conference on Human Factors in Computing Systems, Honolulu, HI, USA. https://doi.org/10.1145/3313831.3376227

Zhou, B., Koerger, H., Wirth, M., Zwick, C., Martindale, C., Cruz, H., . . Lukowicz, P. (2016). Smart soccer shoe: monitoring foot-ball interaction with shoe integrated textile pressure sensor matrix. Paper presented at the Proceedings of the 2016 ACM International Symposium on Wearable Computers, Heidelberg, Germany. https://doi.org/10.1145/2971763.2971784

Zysset, C., Kinkeldei, T., Cherenack, K., \& Tröster, G. (2010). Woven Electronic Textiles: An Enabling Technology for Health-Care Monitoring in Clothing. 